\title{
4-Chlorobenzoyl berbamine, a novel berbamine derivative, induces apoptosis in multiple myeloma cells through the IL-6 signal transduction pathway and increases FOXO3a-Bim expression
}

\author{
JIA-KUN SHEN ${ }^{1,2}$, HUA-PING DU ${ }^{3}$, QIULING MA ${ }^{1}$, MIN YANG ${ }^{1}$, YUN-GUI WANG ${ }^{1}$ and JIE JIN ${ }^{1}$ \\ ${ }^{1}$ Department of Hematology, Institute of Hematology, The First Affiliated Hospital, School of Medicine, \\ Zhejiang University, Hangzhou, Zhejiang 310003; ${ }^{2}$ Department of Hematology, Shangrao People's Hospital, \\ Shangrao, Jiangxi 334000; ${ }^{3}$ Department of Hematology, Sir Run Run Shaw Hospital, School of Medicine, \\ Zhejiang University, Hangzhou, Zhejiang 310016, P.R. China
}

Received February 11, 2013; Accepted April 22, 2013

DOI: $10.3892 /$ or.2013.2431

\begin{abstract}
Multiple myeloma (MM) is an incurable hematopoietic malignancy, although many novel therapeutic agents have been explored. In the present study, we showed that 4-chlorobenzoyl berbamine (BBD9), a novel derivative of berbamine, inhibited the growth of 4 MM cell lines (U266, RPMI 8226, MM1.R and MM1.S). After a 24-h treatment with BBD9, the half maximal inhibitory concentration $\left(\mathrm{IC}_{50}\right)$ values were $1.8,2.3,1.5$ and $2.4 \mu \mathrm{g} / \mathrm{ml}$, respectively, using MTT assays. In BBD9-treated U266 and RPMI 8226 cells, Annexin V (AV)-propidium iodide (PI) staining and FACS analysis demonstrated that apoptosis was involved in this inhibition. This was confirmed by western blot analysis indicating activation and cleavage of caspase-3, $-8,-9$ and PARP. BBD9 also induced $\mathrm{G} 2 / \mathrm{M}$ phase cell cycle arrest in these cells. To investigate the mechanisms responsible for BBD9-induced apoptosis, U266 cells were incubated with 0,1 or $2 \mu \mathrm{g} / \mathrm{ml}$ of BBD9 combined with 0 or $150 \mathrm{ng} / \mathrm{ml}$ of interleukin (IL)-6. MTT assays showed that IL-6 partially abrogated the BBD9-induced cell growth inhibition. Furthermore, BBD9 inhibited autocrine IL-6 production, and downregulated membrane IL-6 receptor (IL-6R) expression. Crucial proteins downstream of the IL-6 signaling pathway, including AKT and STAT3, were inacti-
\end{abstract}

Correspondence to: Professor Jie Jin, Department of Hematology, Institute of Hematology, The First Affiliated Hospital, School of Medicine, No. 79 Qingchun Road, Zhejiang University, Hangzhou, Zhejiang 310003, P.R. China

E-mail: zjuhematology@163.com

Abbreviations: CDK, cyclin-dependent kinase; CDKI, cyclindependent kinase inhibitor; IL-6, interleukin-6; IL-6R, IL-6 receptor; MM, multiple myeloma

Key words: berbamine derivative, IL-6, IL-6 receptor, FOXO3a, multiple myeloma vated in BBD9-treated U266 cells, although exogenous IL-6 did not abrogate this effect. Forkhead transcription factor class 3a (FOXO3a), a nuclear transcription factor downstream from AKT, was upregulated in the nuclei of BBD9-treated U266 cells. Bim, the target gene of FOXO3a, was upregulated at both the protein and mRNA levels, as shown by western blot analysis and quantitative PCR. These results suggest that BBD9 induces apoptosis in MM cells through the inhibition of the IL-6 signaling pathway, leading to FOXO3a activation and upregulation of pro-apoptotic Bim.

\section{Introduction}

Multiple myeloma (MM), which mainly occurs in older patients and particularly in elderly men, is a clonal B-cell malignancy characterized by the abnormal proliferation of plasma cells secreting high levels of abnormal monoclonal immunoglobulin. MM accounts for $10 \%$ of all hematological malignancies (1) and for $20 \%$ of deaths caused by hematological malignancies (2). In the past, alkylating agents such as melphalan, dexamethasone, interferon and vincristine have traditionally been used against MM. In recent years, new agents, including lenalidomide, thalidomide, proteasome inhibitor (bortezomib) and bendamustine, have been introduced into the treatment of MM $(3,4)$. Immunotherapy and hematopoietic stem cell transplantation are also being applied therapeutically to treat $\mathrm{MM}$ patients. At present, the estimated overall survival is higher than $80 \%$ at 3 years. However, despite all the therapeutic advances, MM patients still have a poor prognosis, with a median survival of approximately 3-5 years (5). Consequently, novel agents for the treatment of $\mathrm{MM}$ are urgently needed.

Many cytokines are involved in the proliferation of MM cells and the progression of the disease, including tumor necrosis factor- $\alpha$ (TNF- $\alpha$ ), insulin-like growth factor (IGF), interleukin (IL)-6, vascular endothelial growth factor (VEGF), basic fibroblast growth factor (b-FGF) and hepatocyte growth factor (HGF). Among them, IL-6 is a pivotal cytokine in 
mediating cell proliferation, survival and drug resistance in MM (6). In addition, an increased level of serum IL-6 has been widely recognized as a prognostic factor, associated with a highly malignant phenotype of MM (7). Bone marrow stromal cells constitute one producer of IL-6, while an additional producer of IL-6 are MM cells themselves which show an autocrine response to IL-6, leading to an autocrine proliferation loop (7). IL-6 binds to the IL-6 receptor (IL-6R), a cell surface membrane protein composed of two subunits: an IL-6specific ligand-binding gp80 subunit and a signal transducing gp130 subunit. Binding of IL-6 to IL-6R activates downstream targets, including STAT3, MAPK and AKT (8), followed by a variety of downstream transcription factors, thus promoting the proliferation of myeloma cells.

Berbamine is a herbal compound derived from Berberis amurensis, which is used in Traditional Chinese Medicine. It has been shown to have immunosuppressive (9), anti-inflammatory, antinociceptive and antipyretic activities (10). Berbamine has been previously found to have an antitumor activity in cancer cells including HeLa, SMMC7721 (a hepatoma cell line), K562 and HL-60 cell lines (11-14). Recently, many berbamine derivatives have been synthesized and have been shown to possess potent antitumor activities $(15,16)$. The novel berbamine derivative, 4-chlorobenzoyl berbamine (BBD9), has also been designed for its potent antitumor activity.

In the present study, we investigated the effect of BBD9 on the proliferation of myeloma cells and, for the first time, on the IL-6 signaling pathway. In order to further clarify the mechanism of action of BBD9, we also investigated the downstream targets of IL-6, including the expression of FOXO3a as well as the transcription and expression of Bim, the target gene of FOXO3a, in BBD9-treated MM cells.

\section{Materials and methods}

Cells, culture conditions and reagents. The human myeloma cell lines, U266 and RPMI 8226, were obtained from the Institute of Cell Biology (Shanghai, China). MM1.R and MM1.S cells were kindly provided by Professor Steven Rosen (Northwestern University, Chicago, IL, USA). The cell lines were cultured in RPMI 1640 medium (Gibco) and supplemented with $10 \%$ heat-inactivated fetal bovine serum (FBS) (Gibco), $100 \mathrm{U} / \mathrm{ml}$ penicillin/streptomycin and $2 \mathrm{mmol} / 1$ L-glutamine (Gibco) in a humidified atmosphere with $5 \% \mathrm{CO}_{2}$ at $37^{\circ} \mathrm{C}$. Primary $\mathrm{MM}$ cells were purified from bone marrow aspirates obtained from three patients with de novo MM. BBD9 was kindly provided by Professor Rong-Zhen Xu (The Second Affiliated Hospital, College of Medicine, Zhejiang University, Hangzhou, China). The chemical structure of BBD9 is shown in Fig. 1. BBD9 (molecular weight, 747.25) was dissolved in DMSO and stored at $-20^{\circ} \mathrm{C}$.

MTT assays for cell viability. The in vitro cytotoxic effect of BBD9 on MM cells was determined using an MTT assay. Briefly, exponentially growing cells were plated on 96-well microtiter plates in a total volume of $200 \mu \mathrm{l}$ at densities of $2 \times 10^{5} / \mathrm{ml}$ for cell lines and $5 \times 10^{5} / \mathrm{ml}$ for primary myeloma cells. Following incubation with various concentrations of BBD9 $(0.5-4.0 \mu \mathrm{g} / \mathrm{ml})$ for the indicated times, $20 \mu \mathrm{l}$ of MTT

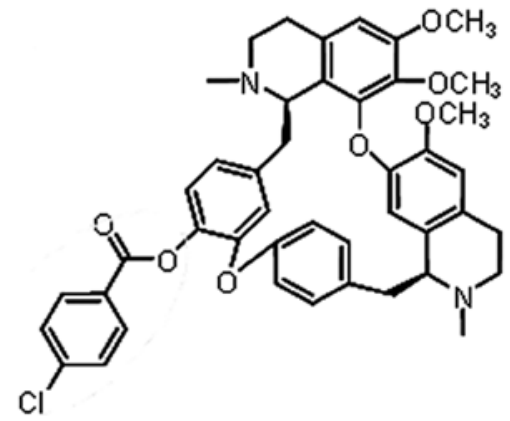

Figure 1. Chemical structure of BBD9.

solution $(5 \mathrm{mg} / \mathrm{ml})$ was added to each well. The plates were incubated for an additional $4 \mathrm{~h}$ at $37^{\circ} \mathrm{C}$. The supernatant was aspirated off and $200 \mu \mathrm{l}$ of DMSO was added to each well to dissolve the purple formazan dye produced by the reduction of MTT in viable cells. The absorbance was measured at $570 \mathrm{~nm}$ using an ELISA plate reader (Bio-Rad).

Flow cytometry assays for determination of apoptosis, cell cycle distribution and IL-6R. Following incubation with the indicated concentrations of agents, the cells were harvested and washed with phosphate-buffered saline (PBS) before the next step. In order to investigate apoptosis, the cells were stained with Annexin V (AV) and propidium iodide (PI) according to the manufacturer's instructions (BioVision). For cell cycle analysis, $\sim 1 \times 10^{6}$ cells were incubated with PI staining solution (containing $8 \mu \mathrm{g} / \mathrm{ml}$ PI, $0.5 \mathrm{mg} / \mathrm{ml}$ RNase A, $1 \%$ Triton X-100), after fixation with cold $70 \%$ ethanol for $30 \mathrm{~min}$. To investigate the expression of IL-6R, the cells were incubated with FITC-conjugated antibody against IL-6R $\alpha$ (Chemicon International). After staining with AV-PI, PI or IL-6R $\alpha$-FITC, the cells were run on a FACSCalibur ${ }^{\mathrm{TM}}$ flow cytometer and analyzed using CellQuest ${ }^{\mathrm{TM}}$ software (Becton-Dickinson). The mean fluorescence intensity was used as a parameter to measure the expression of membrane IL-6R. The immunofluorescent intensity of untreated samples was considered to be $100 \%$. The values for the expression of IL-6R on treated cell membranes were expressed as a percentage of the value for untreated samples.

Western blot analysis. Whole cell lysates were prepared as follows. The cells were suspended in cell lysis buffer (Cell Signaling Technology, Inc.) for $30 \mathrm{~min}$, and the cell suspension was centrifuged at $13,000 \mathrm{x} g$ for $10 \mathrm{~min}$. The resulting supernatant was collected as a whole cell lysate.

Nuclear and cytosolic extracts were isolated using a nuclear extraction kit (Chemicon International). Briefly, after treating with the indicated agents, the cells were collected and suspended in cytoplasmic lysis buffer (no. 90497; Chemicon International) containing $0.5 \mathrm{mM}$ DTT and $1 / 1,000$ protease inhibitor cocktail (no. 90492; Chemicon International). The cell suspension was centrifuged at $8,000 \mathrm{x}$ g for $20 \mathrm{~min}$ at $4^{\circ} \mathrm{C}$. The supernatant containing the cytosolic portion of the cell lysate was collected. The remaining pellet containing the nuclear portion of the cell lysate was resuspended in nuclear extraction buffer (no. 90498; Chemicon International) containing $0.5 \mathrm{mM}$ DTT and 1/1,000 protease inhibitor 


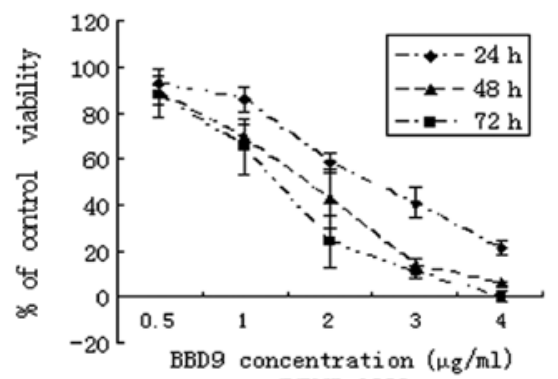

RPMI 8226

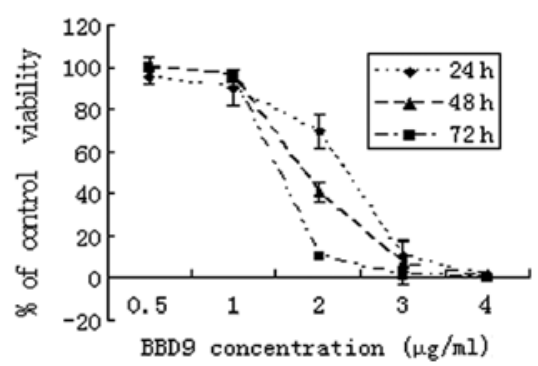

MMI.R

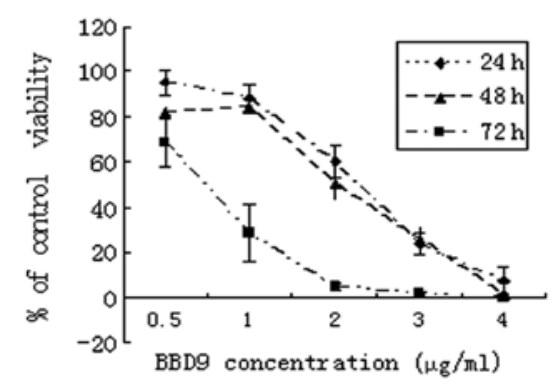

U266

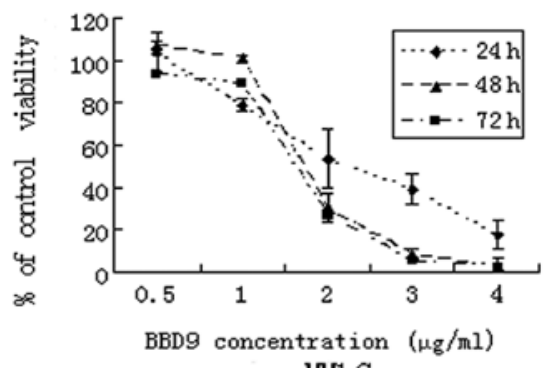

MMI.S

Figure 2. BBD9 exerts a cytotoxic effect on MM cell lines. BBD9 $(0.5-4 \mu \mathrm{g} / \mathrm{ml})$ inhibited the growth of $4 \mathrm{MM}$ cell lines in a dose- and time-dependent manner, as measured by MTT assay over 24-72 h. Data are the means \pm standard error from three independent experiments.

cocktail (part no. 90492; Chemicon International). The nuclear suspension was centrifuged at $16,000 \mathrm{x}$ for $5 \mathrm{~min}$ at $4^{\circ} \mathrm{C}$. The supernatant containing the nuclear portion of the cell lysate was collected and stored at $-20^{\circ} \mathrm{C}$.

Equivalent amounts of protein from each lysate were resolved by $12 \%$ SDS-PAGE gel and electrotransferred onto PVDF membranes (Millipore). The membranes were incubated overnight at $4^{\circ} \mathrm{C}$ with primary antibodies against the following proteins: caspase-3, caspase-8, caspase-9, PARP, AKT, pAKT, STAT3, pSTAT3, cyclin B1, cyclin A, FOXO3a, Bim, $\beta$-actin (Santa Cruz Biotechnology, Inc.) and lamin B. After incubation with the appropriate horsadish peroxidase (HRP)-conjugated secondary antibodies, the proteins were detected using an EZ-ECL kit (Biological Industries).

All antibodies were purchased from Cell Signaling Biotechnology, Inc. (USA) except where other suppliers were indicated.

RNA extraction and real-time PCR. Total RNA was extracted from cells using TRIzol ${ }^{\mathrm{TM}}$ (Invitrogen). Following treatment with BBD9 for $8 \mathrm{~h}$, the cells were harvested and washed twice with PBS. TRIzol was added to lyse the cells. Following the addition of chloroform, the mixture was centrifuged at $12,000 \times \mathrm{g}$ for $15 \mathrm{~min}$. The supernatant containing RNA was collected and isopropanol was added to precipitate the RNA. After further centrifugation, the supernatant was discarded and the pellet containing RNA was washed in $75 \%$ ethanol. The RNA was resuspended in $0.1 \%$ (v/v) DEPC-treated water, and $1 \mu \mathrm{g}$ of total RNA was reverse-transcribed into cDNA using the Invitrogen RT kit and an oligo(dT) primer. Real-time PCR was conducted in a volume of $25 \mu \mathrm{l}$ containing $1 \mu \mathrm{l}$ of primers, $12.5 \mu \mathrm{l}$ of $2 \mathrm{X}$ SYBR Premix EX Taq ${ }^{\mathrm{TM}}$ (Takara), $2 \mu \mathrm{l}$ of sample and $9.5 \mu \mathrm{l}$ of double-distilled water. The samples were amplified in the IQ5 ${ }^{\mathrm{TM}}$ Real-Time PCR system (Bio-Rad) for 40 cycles under the following conditions: denaturation for
$15 \mathrm{sec}$ at $95^{\circ} \mathrm{C}$, annealing and extension for $60 \mathrm{sec}$ at $60^{\circ} \mathrm{C}$. The following primers were used for real-time PCR: Bim forward, 5'-CAC CCA TGA GTT GTG ACA AAT C-3' and reverse, 5'-CGT TAA ACT CGT CTC CAA TAC GC-3'; c-abl forward, 5'-CCG CTG ACC ATC AAT AAG GAA-3' and reverse, 5'-GAT GTA GTT GCT TGG GAC CCA-3'. All the primers were purchased from Sangon Biotech Co., Ltd. (Shanghai).

Enzyme-linked immunosorbent assay (ELISA) for IL-6. Following incubation of U266 cells with BBD9 for $24 \mathrm{~h}$, the level of IL- 6 in the culture supernatant was determined by ELISA according to the manufacturer's instructions (R\&D Systems).

Statistical analysis. Data are shown as the means \pm standard deviation (SD). Data were analyzed using the unpaired Student's t-test. $\mathrm{P}<0.05$ was considered to indicate a statistically significant result.

\section{Results}

BBD9 inhibits MM cell growth and triggers apoptosis. In order to investigate the effects of BBD9 on the viability of MM cells, 4 MM cell lines, RPMI 8226, U266, MM1.R and MM1.S, were exposed to various concentrations of BBD9 for 24, 48 and $72 \mathrm{~h}$, and then analyzed using MTT assays. As shown in Fig. 2, the cell growth of RPMI 8226, U266, MM1.R and MM1.S was inhibited by BBD9 in a time- and dose-dependent manner. The $\mathrm{IC}_{50}$ values, determined after $24 \mathrm{~h}$ of incubation, were $2.3 \mu \mathrm{g} /$ $\mathrm{ml}$ for RPMI 8226, $1.8 \mu \mathrm{g} / \mathrm{ml}$ for U266, $1.5 \mu \mathrm{g} / \mathrm{ml}$ for MM1.R and $2.4 \mu \mathrm{g} / \mathrm{ml}$ for MM1.S. These results suggest that BBD9 is a potent inhibitor of the growth of MM cells in vitro.

Apoptosis is an important part of the mechanism of cell death induced by anticancer agents. We next investigated the role of apoptosis in the inhibition of cell growth in these 
A $\mathrm{BBD} 9(\mu \mathrm{g} / \mathrm{ml})-\mathrm{RPMI} 8226$
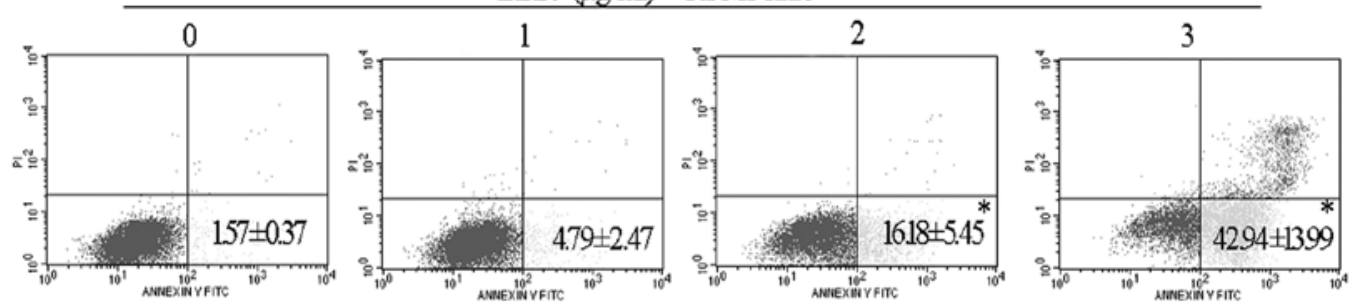

$\mathrm{BBD} 9(\mu \mathrm{g} / \mathrm{ml})-\mathrm{U} 266$
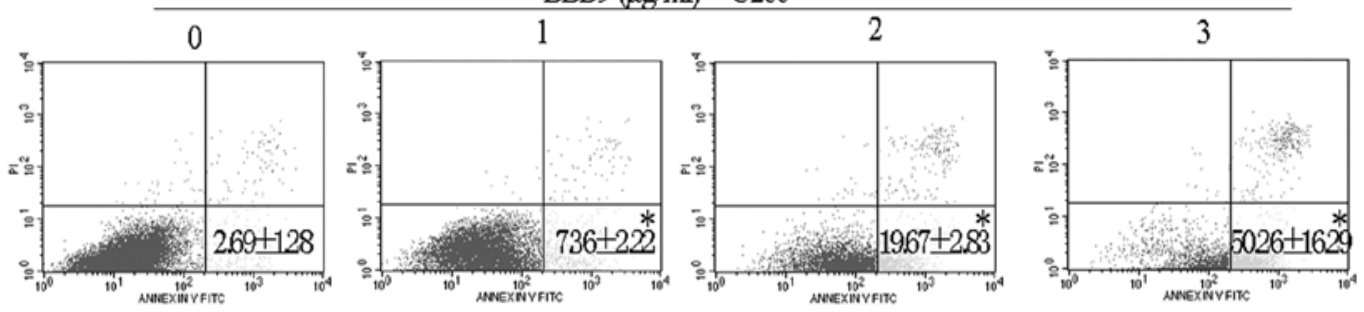

B
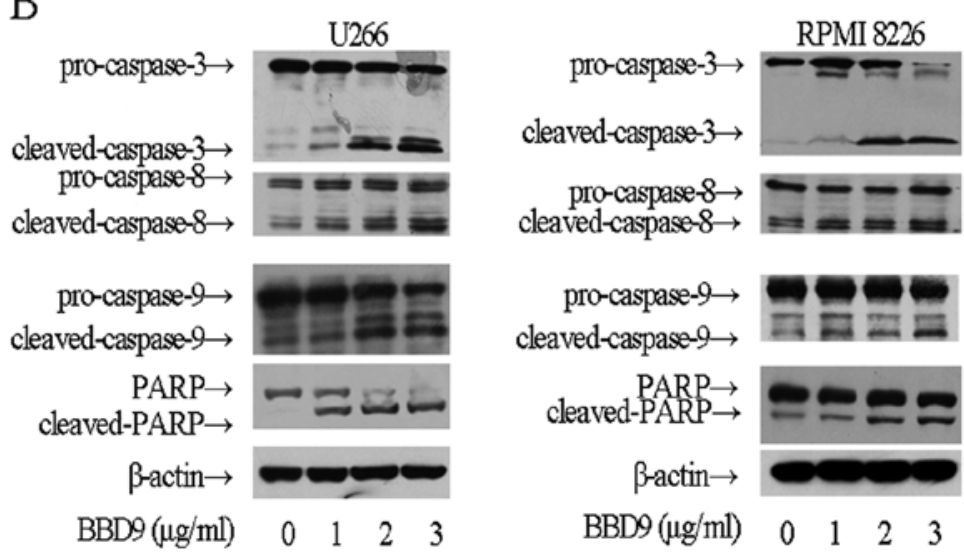

Figure 3. BBD9 induces apoptosis in $2 \mathrm{MM}$ cell lines, as measured by flow cytometry and western blot assays. (A) Flow cytometry of AV-PI-stained RPMI 8226 and $\mathrm{U} 266$ cells treated with $0,1,2$ or $3 \mu \mathrm{g} / \mathrm{ml}$ of BBD9 for $24 \mathrm{~h}$. The results show a marked increase in the percentage of cells in early apoptosis $\left(\mathrm{AV}^{+} \mathrm{PI}\right)$ with increasing BBD9 concentration. Data are the means \pm standard error from three independent experiments. ${ }^{*} \mathrm{P}<0.05$ compared to control cells. (B) Western blots showing cleavage of caspase-3, $-8,-9$ and PARP in U266 and RPMI 8226 cells treated with $0,1,2$ or $3 \mu \mathrm{g} / \mathrm{ml}$ of BBD9 for $24 \mathrm{~h}$. Whole cell lysates were prepared as described in Materials and methods. AV, Annexin V; PI, propidium iodide.

MM cell lines. One of the early events of apoptosis is the translocation of phosphatidylserine (PS) from the internal to the external cell surface (17); this translocated PS is detected by AV staining. Hence, we used AV staining combined with PI staining and flow cytometric analysis. With increasing concentrations of BBD9, the number of U266 and RPMI 8226 cells that were $\mathrm{AV}^{+} \mathrm{PI}^{-}$(indicating the cells in early stages of apoptosis), was significantly increased for $24 \mathrm{~h}$ after treatment (Fig. 3A). Additional characteristic signs of apoptosis include the cleavage of PARP and the activation of caspase-3. Western blot analysis (Fig. 3B) demonstrated that BBD9 induced PARP cleavage and activated caspase-3 in U266 and RPMI 8226 cells in a dose-dependent manner, thus confirming the induction of apoptosis. Furthermore, caspase-8 and -9 were also cleaved in U266 and RPMI 8226 cells (Fig. 3B), indicating that BBD9 induced apoptosis via both mitochondrial-dependent and -independent apoptotic pathways. These data indicate that BBD9 inhibits cell growth and leads to apoptosis in MM cells.

$B B D 9$ induces $G 2 / M$ phase arrest and regulates $G 2 / M$ transition-related proteins in MM cells. To determine whether MM cell growth inhibition induced by BBD9 involves cell cycle changes, we examined the cell cycle phase distribution by flow cytometry. As shown in Fig. 4A, treating U266 and RPMI 8226 cells with increasing concentrations of BBD9 (1-3 $\mu \mathrm{g} / \mathrm{ml})$ for $24 \mathrm{~h}$ resulted in a dose-dependent cell cycle arrest of U266 and RPMI 8226 cells in the G2/M phase. Following incubation with 1,2 or $3 \mu \mathrm{g} / \mathrm{ml}$ of BBD 9 for $24 \mathrm{~h}$, the percentage of cells in the $\mathrm{G} 2 / \mathrm{M}$ phase was markedly increased compared with the controls (Fig. 4A). These results suggest that BBD9 arrests the cell cycle in the $\mathrm{G} 2 / \mathrm{M}$ phase.

The cell cycle is precisely regulated by cyclin, cyclin-dependent kinase (CDK) and CDK inhibitor (CKI). We investigated the levels of proteins involved in $\mathrm{G} 2$ to $\mathrm{M}$ transition by western blot analysis. The results showed that cyclin B1 and cyclin A, proteins known to increase during the G2/M transition phase, were markedly decreased in both U266 and RPMI 8226 cells treated with 1,2 or $3 \mu \mathrm{g} / \mathrm{ml}$ of BBD9 for $24 \mathrm{~h}$, while CDK1 remain unchanged (Fig. 4B).

Cell growth inhibition induced by BBD9 is abrogated by exogenous $I L-6$. In consideration of the important role of IL-6 in 


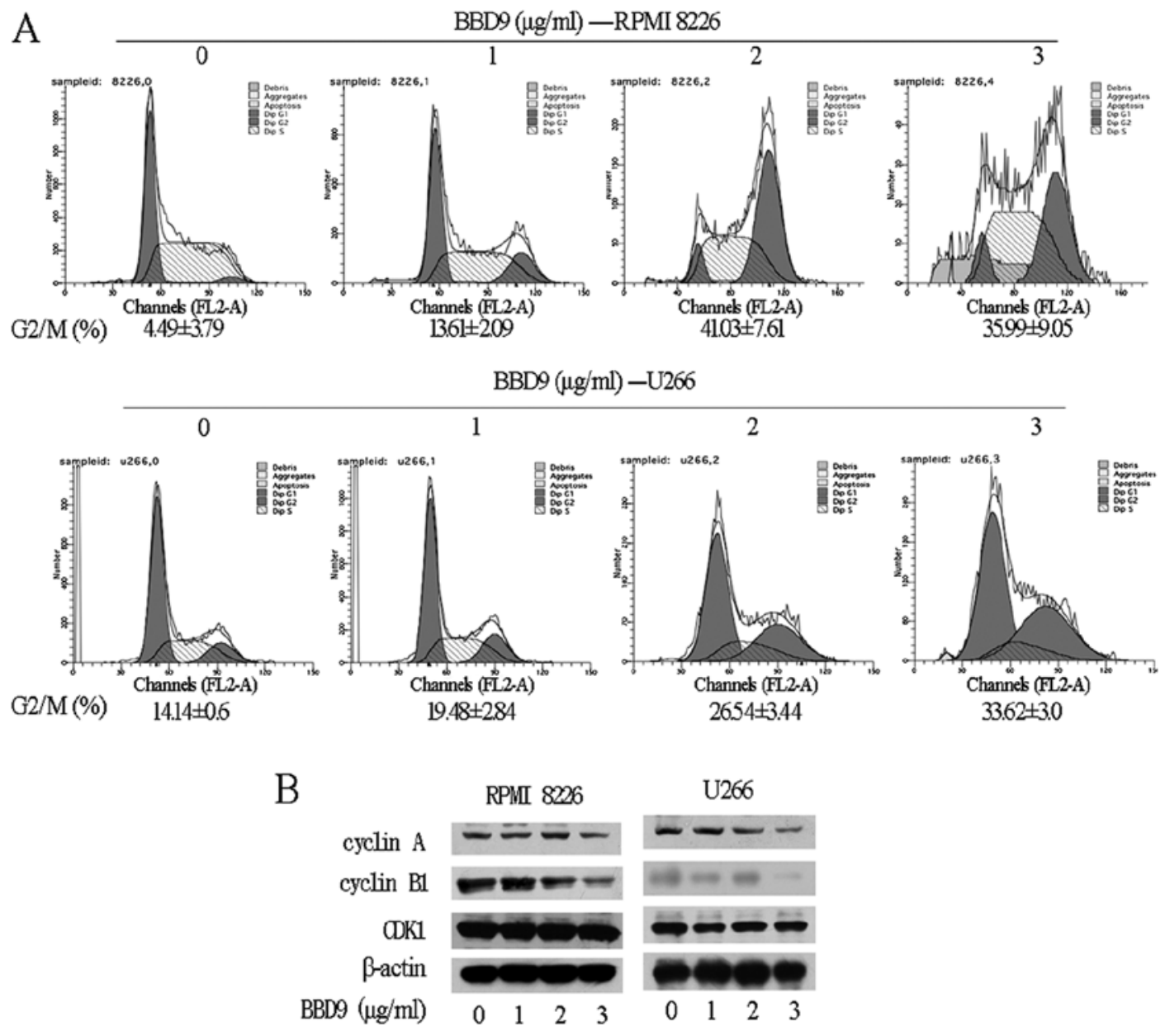

Figure 4. Cell cycle and western blot analyses of G2/M cell cycle regulatory proteins in BBD9-treated MM cells. (A) Cell cycle arrest in the G2/M phase of U266 and RPMI 8226 cells treated with BBD9 $(0,1,2$ or $3 \mu \mathrm{g} / \mathrm{ml}$ for $24 \mathrm{~h})$. The percentage of cells in the G2/M phase is indicated. Data are the means \pm standard error from three independent experiments. (B) Western blot analysis of U266 and RPMI 8226 cells treated with BBD9 ( $0,1,2$ or $3 \mu \mathrm{g} / \mathrm{ml}$ for $24 \mathrm{~h})$, using antibodies against the G2/M cell cycle regulatory proteins cyclin A, cyclin B1 and CDK1. $\beta$-actin was used as a loading control. The blots are from one of three independent experiments with identical results.

the survival and proliferation of MM cells, we next investigated the impact of exogenous IL-6 on BBD9-induced cell growth inhibition by MTT assay. Compared with the cell survival rate of MM cells treated with BBD9 alone, the cell survival rate of cells treated with 1 or $2 \mu \mathrm{g} / \mathrm{ml}$ of BBD9 combined with $150 \mathrm{ng} / \mathrm{ml}$ of IL-6 for $24 \mathrm{~h}$ was significantly increased from $88.83 \pm 5.49$ to $104.83 \pm 4.92 \%$ and from $43.035 \pm 12.77$ to $55.93 \pm 12.24 \%$ (mean $\pm \mathrm{SD}$ ), respectively (Fig. 5A). These results demonstrate that the cell growth inhibition induced by BBD9 is abrogated by exogenous IL-6, indicating that the IL-6 signaling pathway is involved in BBD9-induced apoptosis. We, therefore, proceeded to investigate changes in proteins related to IL-6 signaling in MM cells exposed to BBD9.

BBD9 inhibits IL-6 production and IL-6R expression. One of the characteristics of U266 cells is that they exhibit autocrine IL-6 production and constitutive IL-6R expression; hence, U266 cells constitute a suitable model with which to examine the effects of BBD9 on the IL-6 signaling pathway. We, therefore, used U266 cells to investigate the effects of BBD9 on the IL-6 signaling pathway in the following experiments. We found a significant decrease in IL-6 levels in U266 culture supernatants following treatment with BBD9 for $24 \mathrm{~h}$ using an ELISA assay (Fig. 5E). The expression of IL-6R on the cell surface, as determined by FACS analysis, also decreased significantly in BBD9-treated U266 cells (Fig. 5B). These results suggest that the expression of both IL-6 and IL-6R was inhibited by BBD9 in U266 cells.

BBD9 inhibits STAT3 and AKT activation by exogenous IL-6. STAT3 and AKT are two important downstream targets of IL-6 signaling. Activation of STAT3 and AKT by IL-6 leads to cell survival and proliferation in myeloma cells, while inhibition of the phosphorylation of STAT3 and AKT results in cell death. We first analyzed the effects of BBD9 on STAT3 and AKT in U266 cells. We found that BBD9 markedly inhibited the phosphorylation of STAT3 and AKT in a dose-dependent manner. However, the total amounts of STAT3 and total AKT remained unchanged (Fig. 5C). We then investigated whether BBD9 inhibits the activation of STAT3 and AKT by exogenous IL-6 using western blot analysis. As shown in Fig. 5D, incubation of U266 cells for $24 \mathrm{~h}$ with $150 \mathrm{ng} / \mathrm{ml}$ of IL-6 led to an increase in the phosphorylation of STAT3 and AKT, while this effect was abrogated by treatment with $2 \mu \mathrm{g} / \mathrm{ml}$ of BBD9. 
A

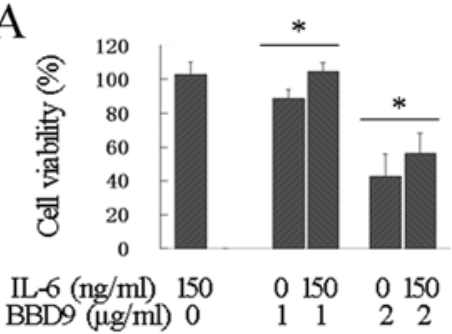

$\mathrm{C}$

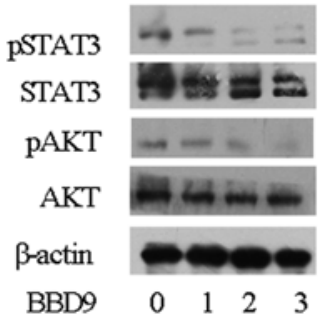

$\mathrm{B}$

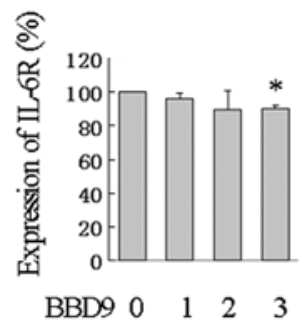

$\mathrm{D}$

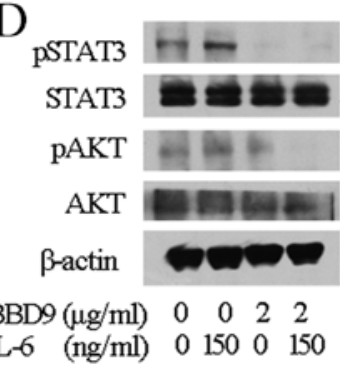

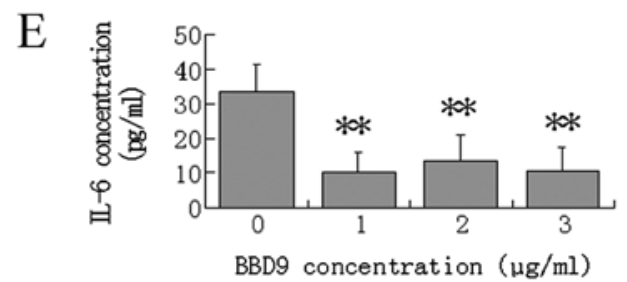

Figure 5. Effects of BBD9 on the IL-6 signaling pathway in U266 cells. (A) Effects of IL-6 on cell growth inhibition induced by BBD9. U266 cells were treated with 0,1 or $2 \mu \mathrm{g} / \mathrm{ml}$ of BBD9 combined with 0 or $150 \mathrm{ng} / \mathrm{ml}$ of IL-6 for $24 \mathrm{~h}$, and the cell viability was determined using MTT assay. ${ }^{*} \mathrm{P}<0.05$ between the two groups indicated. (B) Expression of membrane IL-6R in U266 cells treated with BBD9 $(0,1,2$ or $3 \mu \mathrm{g} / \mathrm{ml}$ for $24 \mathrm{~h})$, as determined using the FITC-conjugated anti-IL-6R antibody and FACS analysis, as described in Materials and methods. ${ }^{*} \mathrm{P}<0.05$ vs. control cells. (C) Western blot analysis of AKT and STAT3 in U266 cells treated with $0,1,2$ or $3 \mu \mathrm{g} / \mathrm{ml}$ of BBD9 for $24 \mathrm{~h}$. (D) Western blot analysis of AKT and STAT3 in U266 cells treated with 0 or $2 \mu \mathrm{g} / \mathrm{ml}$ of BBD 9 combined with 0 or $150 \mathrm{ng} / \mathrm{ml}$ of IL- 6 for $24 \mathrm{~h}$. The blots are representative of three independent experiments with similar results. (E) Effects of BBD9 on IL-6 secretion in U266 cells. The cells were treated with $0,1,2$ or $3 \mu \mathrm{g} / \mathrm{ml}$ of BBD9 for $24 \mathrm{~h}$. The supernatants were collected and the concentration of IL-6 was determined using ELISA assay. Data are the means \pm standard error of three independent experiments. ${ }^{* *} \mathrm{P}<0.01$ vs. untreated control cells.

These results suggest that both the constitutive and exogenous activation of STAT3 and AKT are blocked by BBD9 in myeloma cells.

BBD9 activates FOXO3a and increases the transcription of the Bim gene. FOXO3 is a transcription factor that regulates the transcription of various genes including Bim. Notably, FOXO3 is a target of AKT. The activation of AKT downregulates the expression of FOXO3a. Since AKT phosphorylation was inhibited by BBD9, we hypothesized that FOXO3 is upregulated by BBD9 in MM cells. To test this hypothesis, we first assessed the expression of FOXO3a in nuclear extraction lysate from U266 cells treated with BBD9. We found that FOXO3 was markedly increased as detected by western blot analysis (Fig. 6A). The expression of Bim, one of the targets of FOXO3, was then examined. qRT-PCR assays demonstrated a significant increase in the levels of Bim transcripts
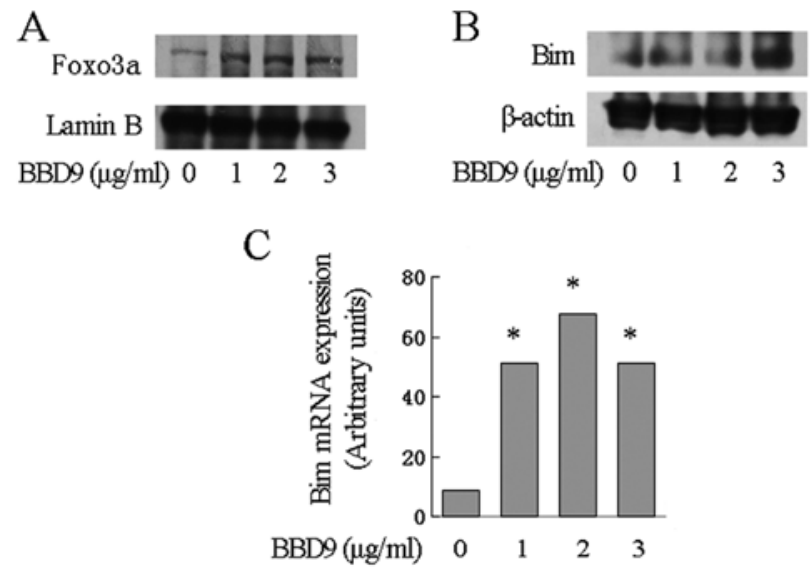

Figure 6. Effects of BBD9 on FOXO3a and Bim expression in U266 cells. (A) Expression of FOXO3a in the nuclei of U266 cells. Cells incubated with $0,1,2$ or $3 \mu \mathrm{g} / \mathrm{ml}$ of BBD9 for $24 \mathrm{~h}$ were subjected to nuclear extraction, as described in Materials and methods; western blot analysis was subsequently used to assess FOXO3a protein levels. Lamin B was used as a loading control. (B) Expression of Bim in U266 cells determined by western blot analysis. U266 cells were treated with $0,1,2$ or $3 \mu \mathrm{g} / \mathrm{ml}$ of BBD9 for $24 \mathrm{~h}$. (C) Quantity of Bim mRNA in U266 cells. RNA was isolated after $8 \mathrm{~h}$ of treatment with 0 , 1,2 or $3 \mu \mathrm{g} / \mathrm{ml}$ of BBD9. Bim mRNA levels were quantified by real-time PCR and are represented as normalized arbitrary units (target gene/housekeeping gene). $\mathrm{C}$-abl was considered as a housekeeping gene. ${ }^{*} \mathrm{P}<0.05$ vs. control cells.

in U266 cells treated with increasing concentrations of BBD9 (Fig. 6C). Notably, the upregulation of Bim transcripts was associated with an increase in the expression of Bim protein as demonstrated by western blot analysis (Fig. 6B).

\section{Discussion}

Apoptosis is a universal and efficient mechanism of programmed cell death, and is an ideal way of removing unwanted, diseased or damaged cells. The induction of apoptosis has been shown to be a promising strategy for the development of novel anticancer agents. In the present study, we showed that BBD9 inhibits the growth of MM cells by triggering apoptosis, as well as inducing cell cycle arrest. BBD9 inhibited cell proliferation in $4 \mathrm{MM}$ cell lines in a dose- and time-dependent manner. Notably, there was no marked difference in susceptibility to BBD9 among the 4 cell lines, where $\mathrm{IC}_{50}$ at $24 \mathrm{~h}$ was $\sim 2 \mu \mathrm{g} / \mathrm{ml}$. These results suggest that BBD9 may be clinically useful in the treatment of patients with MM.

Apoptosis is closely associated with cell cycle arrest in proliferating cells. A large number of anticancer agents have been shown to induce apoptosis by arresting cell cycle progression in the $\mathrm{G} 2 / \mathrm{M}$ phase in various types of cancer. This was confirmed by our study which showed that G2/M phase cell cycle arrest was associated with cell growth inhibition and apoptosis in BBD9-treated myeloma cells. G2/M transition is regulated by the sequential activation and inhibition of cyclins, CDKs and CKIs, including cyclin A, cyclin B1 and CDK1 (also known as cdc2). Among these, the cyclin B1/CDK1 and cyclin $\mathrm{A} / \mathrm{CDK} 1$ complexes are of the utmost importance in regulating the transition from $\mathrm{G} 2$ to $\mathrm{M}$ phase of the cell cycle and mitosis (18-20). In contrast, the inhibition of cyclin B1/CDK1 or cyclin A/CDK1 complex leads to arrest of cell cycle progression in the G2/M phase. The downregulation 
of cyclin B1 and cyclin A, as noted in the present study, was critical in determining the $\mathrm{G} 2 / \mathrm{M}$ arrest in $\mathrm{MM}$ cells caused by BBD9, since CDK1 levels were unaffected. Therefore, the downregulation of cyclin A and cyclin B1 provides a mechanism for G2/M phase arrest in BBD9-treated myeloma cells.

The IL-6 signaling pathway plays an important role in transducing signals for survival and proliferation in myeloma cells (21). Inhibition of the IL-6 signaling pathway leads to cell death and apoptosis. The effects of BBD9 on the expression of IL-6R and IL- 6 have been investigated in a dose range of $1-3 \mu \mathrm{g} / \mathrm{ml}$. The present study demonstrated that both the expression of membrane IL-6R and autocrine IL-6 decreased significantly. It has been reported that exogenous IL- 6 significantly upregulates the expression of membrane IL-6R in myeloma cells although the mechanisms have remained elusive (22). We continue to speculate whether the downregulation of autocrine IL-6, as noted in the present study, results in the decreased expression of IL-6R in myeloma cells.

In addition to the downregulation of IL- 6 and IL-6R by BBD9, we also demonstrated the involvement of downstream elements of the IL-6 signaling pathway in BBD9-induced apoptosis in MM. Two important signal transducers in the IL-6 signaling pathway, STAT3 and AKT, were both found to be inactivated in BBD9-treated myeloma cells in the present study. Even when U266 cells were incubated with exogenous IL-6, STAT3 and AKT were still inactivated. This indicates that the IL- 6 signaling pathway is an important target in the apoptosis induced by BBD9 in MM. The blockade of the IL-6 signaling pathway is a useful strategy for the development of novel therapeutic agents (23).

Bim is a member of the BCL-2 family, which contains more than 20 types of structurally similar proteins, which are divided into two groups: one consisting of pro-apoptotic proteins including Bax, Bim and Bak; and the other consisting of anti-apoptotic proteins including BCL-2, BCL-xL and MCL-1 (24). Bim initiates apoptosis by binding to BCL-2, BCL-xL and MCL-1 $(25,26)$, directly neutralizing their anti-apoptotic function. In the present study, the expression of Bim was elevated in MM cells treated with BBD9 for $24 \mathrm{~h}$, suggesting the involvement of Bim in the apoptosis induced by BBD9.

It has been demonstrated that FOXO3a is a downstream target of AKT (27) and is a critical nuclear factor in regulating transcription of apoptosis-related genes $(28,29)$. By binding to DNA, FOXO3a promotes the transcription of target genes including pro-apoptotic $\mathrm{Bim}(28,30)$. In addition, FOXO3a is inactivated through phosphorylation by activated AKT (27), resulting in the release of bound FOXO3a from DNA, and leading to sustained nuclear exclusion and subsequent inhibition of apoptosis. In contrast, inhibition of AKT induces apoptosis via the upregulation of FOXO3 and Bim. The present study showed that BBD9 inactivated AKT, leading to elevation of the expression of FOXO3a and Bim, at both the transcription and protein levels. Therefore, we confirm that BBD9 induces apoptosis through the AKT/FOXO3a/Bim pathway in MM cells.

In conclusion, BBD9 effectively inhibited cell growth and induced apoptosis in myeloma cells in vitro. The apoptosis induced by BBD9 was accompanied by the arrest of cell cycle progression in the $\mathrm{G} 2 / \mathrm{M}$ phase and concomitant downregulation of cyclin A and cyclin B1. In addition, BBD9 induced apoptosis through the inactivation of the IL- 6 signaling pathway, including the inhibition of the expression of IL-6 and IL-6R, downregulation of STAT3 and AKT phosphorylation, upregulation of FOXO3a in the nucleus and a subsequent increase in the expression of Bim. To conclude, BBD9 is a potential novel therapeutic agent for the treatment of MM. It inactivates the IL-6 signaling pathway, which underlies the molecular mechanisms of apoptosis. These data provide a rationale for the clinical study of BBD9 in patients with MM.

\section{Acknowledgements}

We thank Professor Rong-Zhen Xu (The Second Affiliated Hospital, College of Medicine, Zhejiang University, Hangzhou, China) for kindly providing BBD9. We also thank Dr Wan-Mao Ni for FACS analysis.

\section{References}

1. Barillé-Nion S, Barlogie B, Bataille R, et al: Advances in biology and therapy of multiple myeloma. Hematology Am Soc Hematol Educ Program 2003: 248-278, 2003. doi: 10.1182/asheducation-2003.1.248.

2. Kuehl WM and Bergsagel PL: Multiple myeloma: evolving genetic events and host interactions. Nat Rev Cancer 2: 175-187, 2002 .

3. Richardson PG, Mitsiades C, Schlossman R, Munshi N and Anderson K: New drugs for myeloma. Oncologist 12: 664-689, 2007.

4. Lentzsch S, O'Sullivan A, Kennedy RC, et al: Combination of bendamustine, lenalidomide, and dexamethasone (BLD) in patients with relapsed or refractory multiple myeloma is feasible and highly effective: results of phase 1/2 open-label, dose escalation study. Blood 119: 4608-4613, 2012.

5. Palumbo A, Attal M and Roussel M: Shifts in the therapeutic paradigm for patients newly diagnosed with multiple myeloma: maintenance therapy and overall survival. Clin Cancer Res 17: 1253-1263, 2011.

6. Lauta VM: A review of the cytokine network in multiple myeloma: diagnostic, prognostic, and therapeutic implications. Cancer 97: 2440-2452, 2003.

7. Trikha M, Corringham R, Klein B and Rossi JF: Targeted anti-interleukin- 6 monoclonal antibody therapy for cancer: a review of the rationale and clinical evidence. Clin Cancer Res 9: 4653-4665, 2003.

8. Hideshima T, Nakamura N, Chauhan D and Anderson KC: Biologic sequelae of interleukin-6 induced PI3-K/Akt signaling in multiple myeloma. Oncogene 20: 5991-6000, 2001.

9. Ramgolam V, Ang SG, Lai YH, Loh CS and Yap HK: Traditional Chinese medicines as immunosuppressive agents. Ann Acad Med Singapore 29: 11-16, 2000.

10. Küpeli E, Koşar M, Yeşilada E, Hüsnü K and Başer C: A comparative study on the anti-inflammatory, antinociceptive and antipyretic effects of isoquinoline alkaloids from the roots of Turkish Berberis species. Life Sci 72: 645-657, 2002.

11. Zhao XY, He ZW, Wu D and Xu RZ: Berbamine selectively induces apoptosis of human acute promyelocytic leukemia cells via survivin-mediated pathway. Chin Med J (Engl) 120: 802-806, 2007.

12. Wang GY, Zhang JW, Lu QH, Xu RZ and Dong QH: Berbamine induces apoptosis in human hepatoma cell line SMMC7721 by loss in mitochondrial transmembrane potential and caspase activation. J Zhejiang Univ Sci B 8: 248-255, 2007.

13. Xu R, Dong Q, Yu Y, et al: Berbamine: a novel inhibitor of bcr/abl fusion gene with potent anti-leukemia activity. Leuk Res 30: 17-23, 2006.

14. Li BY, Fu B, Zhao YL and Li WH: Effects of berbamine on intracellular calcium concentration in cultured HeLa cells. Zhongguo Yao Li Xue Bao 20: 1011-1014, 1999.

15. Du HP, Shen JK, Yang M, et al: 4-Chlorobenzoyl berbamine induces apoptosis and $\mathrm{G} 2 / \mathrm{M}$ cell cycle arrest through the $\mathrm{PI} 3 \mathrm{~K} / \mathrm{Akt}$ and $\mathrm{NF}-\kappa \mathrm{B}$ signal pathway in lymphoma cells. Oncol Rep 23: 709-716, 2010. 
16. Cui Y, Xu M, Mao J, Ouyang J, Xu R and Yu Y: Synthesis of berbamine acetyl glycosides and evaluation of antitumor activity. Eur J Med Chem 54: 867-872, 2012.

17. Vermes I, Haanen C, Steffens-Nakken $H$ and Reutelingsperger C: A novel assay for apoptosis. Flow cytometric detection of phosphatidylserine expression on early apoptotic cells using fluorescein labelled Annexin V. J Immunol Methods 184: 39-51, 1995.

18. Dorée M and Hunt T: From Cdc2 to Cdk1: when did the cell cycle kinase join its cyclin partner? J Cell Sci 115: 2461-2464, 2002.

19. Galea CA, Wang Y, Sivakolundu SG and Kriwacki RW: Regulation of cell division by intrinsically unstructured proteins: intrinsic flexibility, modularity, and signaling conduits. Biochemistry 47: 7598-7609, 2008.

20. Toyoshima-Morimoto F, Taniguchi E, Shinya N, Iwamatsu A and Nishida E: Polo-like kinase 1 phosphorylates cyclin B1 and targets it to the nucleus during prophase. Nature 410: $215-220$, 2001.

21. Klein B, Zhang XG, Lu ZY and Bataille R: Interleukin-6 in human multiple myeloma. Blood 85: 863-872, 1995.

22. Kovacs E: Multiple myeloma and B cell lymphoma. Investigation of IL-6, IL-6 receptor antagonist (IL-6RA), and GP130 antagonist (GP130A) using various parameters in an in vitro model. Sc World J 6: 888-898, 2006.
23. Guo Y, Xu F, Lu T, Duan Z and Zhang Z: Interleukin-6 signaling pathway in targeted therapy for cancer. Cancer Treat Rev 38: 904-910, 2012

24. Petros AM, Olejniczak ET and Fesik SW: Structural biology of the Bcl-2 family of proteins. Biochim Biophys Acta 1644: 83-94, 2004.

25. Willis SN, Fletcher JI, Kaufmann T, et al: Apoptosis initiated when $\mathrm{BH} 3$ ligands engage multiple Bcl-2 homologs, not Bax or Bak. Science 315: 856-859, 2007.

26. Hübner A, Barrett T, Flavell RA and Davis RJ: Multisite phosphorylation regulates Bim stability and apoptotic activity. Mol Cell 30: 415-425, 2008.

27. Brunet A, Bonni A, Zigmond MJ, et al: Akt promotes cell survival by phosphorylating and inhibiting a Forkhead transcription factor. Cell 96: 857-868, 1999.

28. Barreyro FJ, Kobayashi S, Bronk SF, Werneburg NW, Malhi $\mathrm{H}$ and Gores GJ: Transcriptional regulation of Bim by FoxO3A mediates hepatocyte lipoapoptosis. J Biol Chem 282: 27141-27154, 2007.

29. Modur V, Nagarajan R, Evers BM and Milbrandt J: FOXO proteins regulate tumor necrosis factor-related apoptosis inducing ligand expression. Implications for PTEN mutation in prostate cancer. J Biol Chem 277: 47928-47937, 2002.

30. Burgering BM and Kops GJ: Cell cycle and death control: long live Forkheads. Trends Biochem Sci 27: 352-360, 2002. 